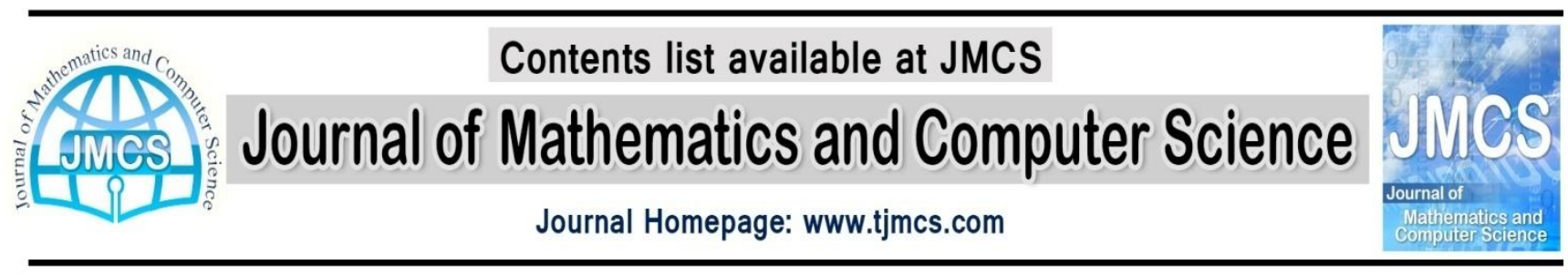

\title{
Measure Efficiency by DEA model
}

\author{
Adel Asgari Safdar ${ }^{1}$ \\ ${ }^{1}$ Department of Applied Science, Faculty of mathematical, University of Qom, Qom, Iran \\ amir9002001@yahoo.com
}

\begin{abstract}
Article history:
Received April 2014

Accepted May 2014

Available online May 2014
\end{abstract}

\begin{abstract}
Parametric methods of efficiency measurement include the Stochastic Frontier Approach (SFA), Thick Frontier Approach (TFA) and Distribution Free Approach (DFA). These methods measure economic efficiency. Economic efficiency is a broader term than technical efficiency. It covers an optimal choice of the level and structure of inputs and outputs based on reactions to market prices. Basic efficiency is a ratio of output over input. To improve efficiency one has to either: (1) increase the outputs, (2) decrease the inputs, (3) if both outputs and inputs increase, the rate of increase for outputs should be greater than the rate of increase for inputs, or (4) if both outputs and inputs are decreasing, the rate of decrease for outputs should be lower than the rate of decrease for inputs.
\end{abstract}

Keywords: DEA (Data Envelopment Analysis), Model, Efficiency

\section{Introduction}

It is one of the key activities for any firm to monitor its efficiency. In our modern society, there is a number of methods based either on the traditional approach or using IT. Efficiency measurement methods can be divided into three main categories: ratio indicators, parametric and nonparametric methods. In selecting indicators to gauge efficiency we focus primarily on a firm's inputs and outputs. DEA models can generate new alternatives to improve performance compared to other techniques [7]. Linear programming is the backbone of DEA methodology that is based on optimization platform. Hence, what differentiates the DEA from other methods is that it identifies the optimal ways of performance rather than the averages. In today's world, no health care institution can afford to be an average performer in a competitive health market. The measurement of efficiency in production units and the identification of sources of their inefficiency is a precondition to improve the performance of any productive unit in a competitive environment. Generally speaking, the term productive unit refers to a unit producing certain outputs by spending certain inputs. 


\section{Efficiency Measures}

Identification of optimal performance leads to benchmarking in a normative way. Using DEA health care managers can not only to identify top performers, but also discover the alternative ways to stir their health care organizations into becoming one of the best performers.

DEA has been subject to countless research publications, conferences, dissertations, and applications within both the non-profit and for-profit sectors [1]. Until now, the use of DEA within health care has been limited to conference sessions and research publications [6]. Thus health care managers have not adopted DEA as a standard tool for benchmarking and decision-making. Part of this is due to its complicated formulation and to the failure of DEA specialists to adequately bridge the theory-practice gap.

DEA is a comparative approach for identifying performance or its components by considering multiple resources that are used to achieve outputs or outcomes in health care organizations. These evaluations can be conducted not only at the organization level, but also in sub-units, such as departmental comparisons, where many areas of improvement in savings of particular input resources or strategies to augment the outputs can be identified.

Banks, or bank branches, can be treated as production units too. In general, they are homogeneous units performing the same or similar activities. All inputs and outputs have an impact on efficient operation of such units, even though some are considered more or less important.

\section{Sample Model:}

The most frequent method used to measure efficiency is based on ratios. Their handicap is that they reflect only a few of the factors having an impact on the overall.

Efficiency of a productive unit. Say we have a population of $\mathrm{n}$ productive units DMU1, DMU2... DMUn. Each unit produces $s$ outputs while consuming $m$ inputs. Let us write an input matrix $X=[x i j, i=$ $1,2, \cdots, m, j=1,2, \cdots, n]$ and an output matrix $Y=[y i j, i=1,2, \cdots, s, j=1,2, \cdots, n]$. The q-th line - i.e. $\mathrm{Xq}$ and $\mathrm{Yq}-$ of these matrixes thus shows quantified inputs/ outputs of unit DMUq[4,5]. The efficiency rate of such a unit can then be generally expressed as:

$$
\frac{\text { weighted sum of outputs }}{\text { weighted sum of inputs }}=\frac{\sum_{i=1}^{s} u_{i} y_{i q}}{\sum_{j=1}^{m} v_{j} x_{j q}}
$$

Where:

$\mathrm{vj}, \mathrm{j}=1,2, \cdots, \mathrm{m}$, are weights assigned to $\mathrm{j}$-th input,

ui, $\mathrm{i}=1,2, \cdots, \mathrm{s}$, are weights assigned to $\mathrm{i}$-th output.

There are several ways to estimate the efficiency rate as defined above, namely multicriterial decision methods and data envelopment analyses (DEA). These approaches differ in how they obtain input and output weights.

Multicriterial decision methods usually expect the user to define the weights vj and ui upfront, i.e. the user determines the significance of individual inputs and outputs in the analysis. Such an analysis yields the rate of utility of given units. It reflects the relative importance of inputs and outputs represented by their respective weights. Based on this analysis units can be ranked from the worst to the best performer [8]. 
DEA models derive input and output weights by means of an optimizing calculation. Based on that, units can be classified into efficient and inefficient. In inefficient units, they tell us target values of inputs and outputs which would lead to efficiency.

\section{Technical Efficiency}

Consider Hospital a treating brain tumor using the Gamma-Knife technology. Hospital A can provide 80 procedures per month with $120 \mathrm{~h}$ of neurosurgeon time. Last month, Hospital A produced 60 procedures while neurosurgeons were on the premises for $120 \mathrm{~h}$. The best achievable efficiency score for Hospital A is 0.667 (80/120), while due to their output of 60 procedures, their current efficiency score is $0.5(60 / 120)$ [4].We assess that Hospital $\mathrm{A}$ is operating at $75 \%(0.75=0.5 / 0.667)$ efficiency. This is called technical efficiency. In order for Hospital A to become technically efficient, it would have to increase its current output by 20 procedures per month [2].

\section{Data Envelopment Analysis (DEA) in ONE Hospital}

DEA essentially forms a frontier using the efficient organizations. To illustrate the conceptualization of the DEA frontier, consider the performance ratios (Table 1) of the first five hospitals from the example in Chap. 1. Here we consider two inputs, nursing hours and medical supplies, by dividing them by inpatient admissions; thus we obtain standardized usage of each input per inpatient admission.

Table1. Hospital performance ratios

\begin{tabular}{lcc}
\hline Provider ID & $\begin{array}{c}\text { Nursing } \\
\text { hours/inpatient } \\
\text { admissions }\end{array}$ & $\begin{array}{c}\text { Medical } \\
\text { supplies/inpatient } \\
\text { admissions }\end{array}$ \\
\hline H1 & $\mathbf{1 . 3 9}$ & 6.55 \\
H2 & 3.89 & 13.33 \\
H3 & 1.51 & 5.48 \\
H4 & 3.93 & 2.59 \\
H5 & 2.31 & 4.56 \\
H6 & 1.91 & 7.94 \\
H7 & 1.44 & 28.72 \\
H8 & 2.64 & 3.94 \\
H9 & 2.96 & 21.16 \\
H10 & 3.15 & 8.49 \\
\hline
\end{tabular}

\section{Model Orientation}

As in ratio analysis, when we calculate efficiency output over input, and place emphasis on reduction of inputs to improve efficiency, in DEA analysis this is called input orientation [2]. Input orientation assumes health care managers have more control over the inputs rather than arriving patients either for outpatient visit or admissions. Figure 1 is an example of an input-oriented model, where H6 must reduce its inputs to achieve efficiency. 


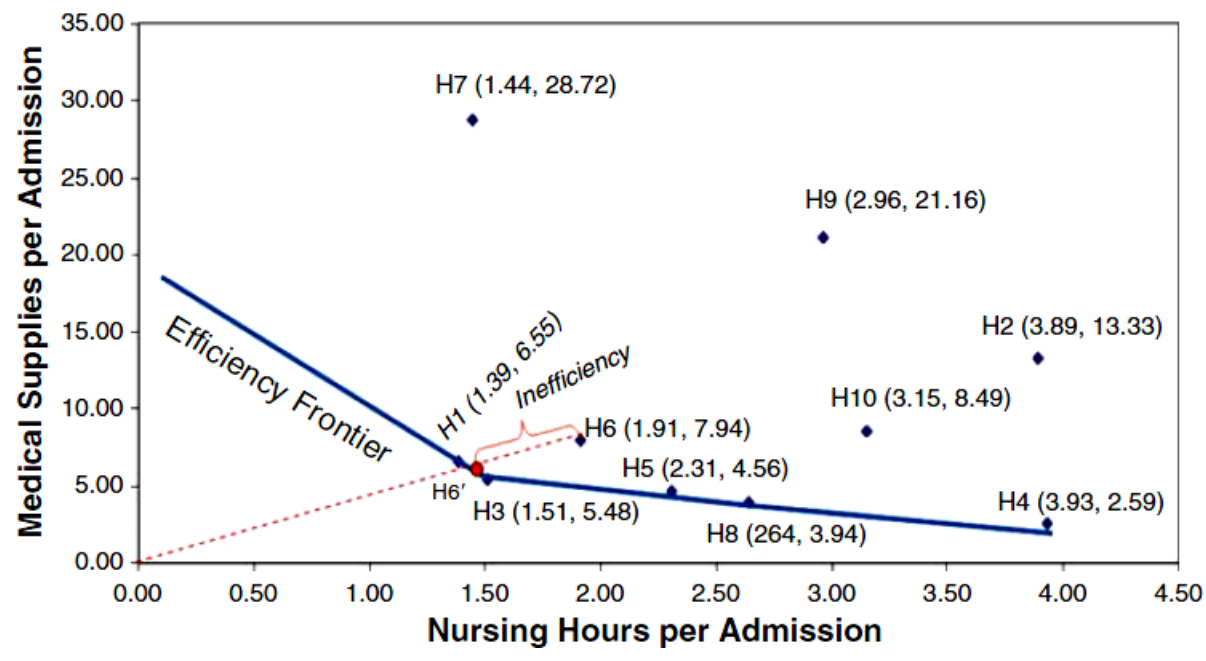

Figure1. Efficiency frontier [4]

\section{Output-Oriented Models}

The essence of output orientation comes from how we look at the efficiency ratios. When we illustrated the input orientation we used the ratios in which inputs were divided by outputs. Hence we can do the opposite by dividing outputs by inputs, and create reciprocal ratios. We can calculate these mirror ratios as shown in Table (2) below [1]. The first two columns show two different outputs, inpatient admissions and outpatient visits, being divided by the same input, nursing hours. The higher ratio values here would mean better performance for the hospitals.

Table2. Hospital performance ratios [4]

\begin{tabular}{lcc}
\hline Provider ID & $\begin{array}{c}\text { Inpatient admissions/ } \\
\text { nursing hours }\end{array}$ & $\begin{array}{c}\text { Outpatient visit/ } \\
\text { nursing hours }\end{array}$ \\
\hline H1 & 0.72 & 0.37 \\
H2 & 0.26 & 0.24 \\
H3 & 0.66 & 0.42 \\
H4 & 0.25 & 0.03 \\
H5 & 0.43 & 0.21 \\
H6 & 0.52 & 0.25 \\
H7 & 0.69 & 0.37 \\
H8 & 0.38 & 0.11 \\
H9 & 0.34 & 0.55 \\
H10 & 0.32 & 0.23 \\
\hline
\end{tabular}

\section{Conclusion}

Finally, DEA provides the identification of a "peer group," a group of reference or comparison. For a firm under evaluation, its reference group corresponds to those firms with lambda different from zero in (1), the lambda value providing information on the importance of each firm within a group. On the other 
hand, with the use of DEA, it is possible to have a better identification of the efficiency required to compare distribution companies.

\section{ACKNOWLEDGEMENTS}

The author thanks so much to Dr. Amir HosseinAsgari, IA University, for proof-editing.

\section{References}

[1] A., Charnes, Cooper, W. W., \& Rhodes, E. Measuring the efficiency of decision making units. European Journal of Operational Research, 2, 429-444. (1978)

[2] Jamasb T. and Pollitt M., "Benchmarking and regulation of electricity distribution and transmission utilities: Lessons from international experience," in DAE Working Paper. Cambridge, U.K.: Department of Applied Economics, Univ. Cambridge. (2001)

[3] Machine component grouping solutions via data envelopment analysis. IEEE Transactions on Engineering Management, 44(3), 299-304.

[4] Y.Ozcan, A. Health Care Benchmarking and Performance Evaluation An Assessment using Data Envelopment Analysis (DEA) DEAFrontier Software Included Series: International Series in Operations Research \& Management Science, Vol. 120.Springer. (2008)

[5] T. Sexton, R., Silkman, R. H., \& Hogan, A. Data envelopment analysis: Critique and extensions. In R. H. Silkman(Ed.), Measuring efficiency: An assessment of data envelopment analysis. Publication no. 32 in the series New Directions of Program Evaluation, Jossey Bass, San Francisco. (1986)

[6] S.Talluri, \&Sarkis, J. Extensions in efficiency measurement of alternate(1997)

[7] S.Talluri, ,\& Yoon, K. P.. A cone-ratio DEA approach for AMT justification. International Journal of Production Economics. (2000)

[8] R.Thompson, G., Singleton, F. D., Thrall, . M., \& Smith, B. A.. Comparative site evaluations for locating a high energy physics laboratory in Texas. Interfaces, 16, 35-49. (1986). 